\title{
MACHINABILITY OF NICKEL AND TITANIUM ALLOYS UNDER OF GAS-BASED COOLANT-LUBRICANTS (CLS) - A REVIEW
}

\author{
A.E.I.Elshwain ${ }^{1}$, Norizah Redzuan ${ }^{2}$, Noordin Mohd Yusof ${ }^{3}$ \\ ${ }^{1}$ PhD student $1^{\text {st }}$ year, ${ }^{2}$ Doctor, ${ }^{3}$ Professor, Faculty of Mechanical Engineering,Universiti Teknologi Malaysia, 81310 \\ UTM Skudai, Johor, Malaysia, elshwion@gmail.com,norizah@mail.fkm.utm.my,noordin@fkm.utm.my
}

\begin{abstract}
Advanced materials like nickel and titanium have unique combinations such as low thermal conductivity, high chemical reactivity and hardness. All of these properties are desirable to be used as suitable lubricant and proper cooling technique for increasing tool life, decreasing cutting temperature and improving surface roughness. This paper presents a literature review done on gasbased coolant-lubricants (CLs) which used in the form either gas or cooled-pressured gases. Investigation of previous researches with different approaches which have been used on machining operation that effect on cutting temperature, tool wear and surface roughness. As a result, gas-based coolant-lubricants (CLs) has been determined as one of the most suitable cooling process for machining cutting operation in terms of improvement in tool life and surface roughness. Furthermore, this type of cooling process is considered as one of environmentally conscious machining.
\end{abstract}

Index Terms: Gas-based coolant-lubricants (CLs), nickel and titanium alloys, tool wear, surface roughness and integrity, green machining.

\section{INTODUCTION}

In aerospace industry, the materials mostly used are nickel and titanium and their alloys, offer unique combination of properties like high strength at elevated temperatures, resistance to chemical degradation, and wear resistance [1]. These materials are referred to as difficult-to-cut since they pose a greater challenge to machining processes such as turning, milling and drilling due to the high temperatures and stresses generated during machining [2]. The poor thermal conductivity of these materials result in the concentration of high temperatures at the tool workpiece and tool-chip interfaces, consequently accelerating tool wear, also their poor thermal properties also prevent from producing good surface results at elevated temperatures due to deformation and friction induced heat and microstructural changes. The use of cutting fluid for cooling and lubrication in machining nickel and titanium and their alloys is generally advised to dissipate the heat generated during machining, thus reducing tool wear and improving the tool life [3]. However, applications of conventional cutting fluids in industry create several health and environmental problems, particularly in regard to their degradation and ultimate disposal is a major problem [4]. On the other hand, the environmental and health hazards associated with the use of these fluids together with developing governmental regulations have resulted in increasing machining costs [5]. New approaches for reducing cutting fluids application in machining processes are to use gas-based CLs in order to dissipate the generated heat at the cutting zone and enhance the machinability through the changes in cutting tool/workpiece material properties. The gas-based CLs include: compressing, cooling and liquefying such as compressed chilled air, compressed chilled gases and liquid nitrogen $\left(\mathrm{LN}_{2}\right)$. These approaches present an innovative method of cooling the cutting tool or/and part during machining. Main gas-based CLs are air, nitrogen, argon, helium or carbon dioxide. They might be used in conjunction with traditional cutting fluids in the form of mist or droplets to enhance their lubrication capability [5]. Gaseous cooling appears very attractive when the cutting fluid penetration problem is considered. such as argon, helium and nitrogen are sometimes used to prevent oxidation of the workpiece and the chips [5, 6]. In cryogenic cooling used with extremely low temperatures to achieve process cooling. The best known cryogens are liquid hydrogen (boiling point: $20.268 \mathrm{~K}=-252.882{ }^{\circ} \mathrm{C}$ ), liquid nitrogen (boiling point: $77.35 \mathrm{~K}=195.80{ }^{\circ} \mathrm{C}$ ), liquid oxygen (boiling point: $90.18 \mathrm{~K}=-182.97{ }^{\circ} \mathrm{C}$ ) and dry ice $/ \mathrm{CO}_{2}$ snow (sublimation point $194.5 \mathrm{~K}=-78.5^{\circ} \mathrm{C}$ ). Liquid nitrogen (often referred to by the abbreviation, $\mathrm{LN}_{2}$ ) is the most commonly used element in cryogenics. This is due to their good availability and relatively safe and easy handling [5, 7]. Therefore, using $\mathrm{LN}_{2}$ in machining operations could be determined as enabling substantial improvement in tool life and surface finish-dimensional accuracy through reduction in tool wear through control of machining temperature desirably at the cutting zone [8].

\section{NICKEL -BASED ALLOYS}

Nickel based alloys are known as some of the most difficultto-machine super alloys in order to satisfy production and quality requirement. They are the most complex of the superalloys and are used in the hottest parts of aircraft engines, constituting over $50 \%$ of the engine weight. They provide higher strength to weight ratio compared to steel which is denser. Other applications include power generation turbine components, as well as in petrochemical, 
food processing, nuclear reactor, and pollution control equipment. The use of these alloys in such aggressive environments hinges on the fact that it maintains high resistance to corrosion, mechanical and thermal fatigue, mechanical and thermal shock, creep and erosion at elevated temperatures. These properties are required for the efficient and effective service performance of the domains in which the alloys are used [9-12]. Nickel-base alloys can be strengthened by two methods: through solid solution strengthening or by being hardened through intermetallic compound precipitation in FCC matrix. (Alloys such as Inconel 625 and Hastelloy $\mathrm{X}$ are solid solution strengthened, may get additional strengthening from carbide precipitation). Alloys such as Inconel 718, however, are precipitation strengthened. A third class of nickel-base superalloys, typified by MA-754, is strengthened by dispersion of inert particles such as yttria $\left(\mathrm{Y}_{2} \mathrm{O}_{3}\right)$, and in some cases with $\gamma^{\prime}$ (gamma prime) precipitation (MA$6000 \mathrm{E})$. these alloys are available in both cast and wrought forms. Highly alloyed compositions, such as Rene 95, Udimet 720, and IN100, are produced by powder metallurgy followed by forging. For the above wrought alloys and cast alloys (Rene 80 and Mar-M- 247), the strengthening agent is $\gamma^{\prime}$ precipitate. For Inconel 718, $\gamma^{\prime \prime}$ (gamma double prime) is the primary strengthening agent. Alloys that contain niobium, titanium, and aluminum, such as Inconel 725, are strengthened by both $\gamma^{\prime}$ and $\gamma^{\prime \prime}$ precipitates. The nickel based alloys contain at least $50 \%$ nickel and are characterized by the high phase stability of the FCC austenitic (y) matrix. Many nickel based alloys contain 10-20\% chromium, up to about $8 \%$ aluminum and titanium combined, $5-15 \%$ cobalt, and small amounts of boron, zirconium, hafnium and carbon [9]. Chemical compositions of most common nickel-based alloys are listed in Table 1. It is reported that nickel-based alloys compose over half of the materials used in the aerospace industry, and aero engines utilize IN-718 material greatly [11].

\section{TITANIUM ALLOYS}

Titanium and its alloys are attractive materials in many engineering fields such as aerospace, because of their superior mechanical and physical properties such as: high strength to weight ratio, high yield stress which is maintained at elevated temperature and their exceptional resistance to corrosion. They are also being used increasingly in other industrial and commercial applications, such as petroleum refining, chemical processing, surgical implantation, pulp and paper, pollution control, nuclear waste storage, food processing, electrochemical (including cathodic protection and extractive metallurgy) and marine applications [5]. Titanium alloys are classified into four main groups namely $\alpha$, near $\alpha, \alpha / \beta$ and $\beta$, based on the composition and the resultant room temperature constituent phases [10-13].

\section{1 a Alloys}

The $\alpha$ alloys contain predominantly $\alpha$ phase at temperatures up to well above $540{ }^{\circ} \mathrm{C}$, these alloys possess excellent tensile properties and creep stability at room and elevated temperatures up to $300{ }^{\circ} \mathrm{C}$. $\alpha$-alloys are used chiefly for corrosion resistance and cryogenic applications.

\section{2 $\alpha-\beta$ Alloys}

$\alpha-\beta$ Alloys contain one or more of the $\alpha$ and $\beta$ stabilizers. These alloys retain more $\beta$ after final heat treatment than the near $\alpha$ alloys and can be strengthened by solution treating and aging, although they are generally used in the annealed condition, e.g. Ti 6-4 (Ti- 6AI-4V) and Ti-6-6-2 (Ti-6Al$2 \mathrm{Sn})$. Ti 6-4 alloy is the most common comprising about $45 \%$ to $60 \%$ of the total titanium production, it can be heattreated to high strength levels and hence are used mainly for high-strength applications at elevated temperatures up to about $350{ }^{\circ} \mathrm{C}$.

\section{3 $\beta$ Alloys}

$\beta$ Alloys have more $\beta$-stabilizer content and less $\alpha$ stabilizer than $\alpha-\beta$ alloys. These alloys contain significant quantities of $\beta$-stabilisers and are characterised by high hardenability, improved forgeability and cold formability, as well as high density, e.g.Ti-3V-11Cr-3Al (Ti-10-2-3) and Ti-3AL-8V$6 \mathrm{Cr}-4 \mathrm{Mo}-4 \mathrm{Zr}$, (Ti-10-2-3) is finding increasing use in the aerospace frame industry due to the growing requirements for high strength at lower temperatures.

\subsection{Near- $\alpha$ titanium alloy}

These alloys contain-stabilisers (Al, Sn) in addition to minor $\beta$-stabilisers (Mo and $\mathrm{V}$ ) . At room temperature the microstructure is chatacterised mainly by $\alpha$-phase with little $\beta$-phase. These alloys mainly used at operating temperature between 400 and $520{ }^{\circ} \mathrm{C}$, e.g. Ti-8Al-1Mo-1V (Ti-811) (a near $\alpha$ alloy) which is used for compressor blades and wheels and Ti-6Al-2,7Sn-4Zr-0,4Mo-0,45Si (Ti-1100 (a near $\alpha$ alloy) which is the most creep resistant of all titanium alloys .

Table 1. Chemical composition of most common nickel-based alloys [12]

\begin{tabular}{|c|c|c|c|c|c|c|c|c|c|c|c|c|}
\hline \multirow[t]{2}{*}{ Alloys } & \multicolumn{12}{|c|}{ Chemical composition $(\%)$} \\
\hline & $\mathrm{Ni}$ & $\mathrm{Cr}$ & Co & $\mathrm{Fe}$ & Mo & W & $\mathrm{Nb}$ & $\mathrm{C}$ & Mn & $\mathrm{Si}$ & $\mathrm{Al}$ & $\mathrm{Ti}$ \\
\hline Iconel 718 & 52.5 & 19.0 & 1.0 & 19.0 & 3.0 & & & 0.04 & 0.4 & 0.9 & 0.9 & 0.9 \\
\hline Inconel 706 & 42.0 & 16.0 & & 40.0 & & & & 0.03 & 0.2 & 0.3 & 0.4 & 1.8 \\
\hline Inconel 625 & 62.0 & 21.0 & & 5.0 & 9.0 & 0.6 & & 0.04 & 0.5 & 0.5 & 0.4 & 0.4 \\
\hline Hastelloy S & 67.0 & 16.0 & & 3.0 & 15.0 & & & 0.02 & 0.5 & 0.4 & & \\
\hline Hastelloy X & 47.0 & 22.0 & 1.5 & 18.0 & 9.0 & & & 0.10 & 1.0 & 0.5 & & \\
\hline $\begin{array}{l}\text { Nimonic } \\
\text { PK33 }\end{array}$ & 55.9 & 18.0 & 14.0 & 0.5 & 7.0 & & & 0.05 & 0.3 & 0.3 & 2.1 & 2.2 \\
\hline Udimet 720 & 56.0 & 16.0 & 14.7 & & 3.0 & 1.3 & & & & & 2.5 & 5.0 \\
\hline Waspaloy & 58.0 & 19.0 & 13.5 & 0.8 & 4.5 & & & 0.07 & 0.1 & 0.1 & 1.4 & 3.0 \\
\hline
\end{tabular}

\section{MACHINABILITY OF NICKEL-BASED}

\section{ALLOYS}

Possible reasons for making nickel-based alloys difficult-tocut are listed below [11, 12, 14, 15]:

1) Austenitic matrix, and like stainless steels, work harden rapidly during machining; 2) Localization of shear in the chip produces abrasive saw-toothed edges which make swarf handling difficult; 3) Tendency to weld with the tool material at the high temperature generated during machining which deteiorates machined surfaces as well as worsening 
componenets integrity; 4) The tendency to form a BUE during machining and the presence of hard abrasive carbides in their microstructure also deters machinability; 5) The high strength of nickel-base superalloys at cutting temperatures causes high cutting forces, generates more heat at the tool tip (compared to alloy steel machining), and limits their speed capability; 6) The high capacity for work hardening in nickel-base alloys causes depth-of-cut notching on the tool, which can lead to burr formation on the workpiece;7)Low thermal diffusivity, leading to localisation of temperatures (more than $1000{ }^{\circ} \mathrm{C}$ ) at the tool tips to cuase high thermal gradient.

\section{MACHINABILITY OF TITANIUM ALLOYS}

Poor machinability of titanium alloys due to their inherent characteristics, which lists as following [10-13, 16, 17]:

1) In machining and grinding of titanium alloys, their surface is easily damaged during machining and grinding operations due to their poor machinability, damage appearing in the form of microcracks, built-up edge, plastic deformation, heat-affected zones, and tensile residual stresses; 2) The high work-hardening tendency of titanium alloys can also contribute to the high cutting forces and temperatures that may lead to depth-of-cut notching; 3)The low modulus of elasticity of titanium alloys was cited as the main cause of chatter during machining, as titanium deflects nearly twice as much as carbon steel with the greater springback behind the cutting edge resulting in premature flank wear, vibration, and higher cutting temperature; 4) Low heat conductivity of titanium, which adversely affects tool life, and the ease of damaging the titanium surface; 5) Chemically reactive leading to a tendency for welding to the tool, chipping, and premature failure; 6) High dynamic shear strenght during cutting process, resulting localisation of shear stress and the production of abrasive saw-tooth edges which encourages notching of cutting tools 7) Titanium's chip is very thin with consequently an unusually small contact area with the, which causes high stresses on the tip of the tool. The combination of a small contact area and the low thermal conductivity results in very high cutting temperatures.

\section{GASES AND CHILLED AIR}

Gas-based CLs generally refers to the substances that at room temperature are in gas form, however in machining applications they are used in the form of either gas compressing, cooling and liquefying fluids. Main gas based CLs are: air, oxygen, nitrogen, argon and carbon dioxide, physical properties of these gags as shown in Table 2. The gas-based CLs might be used in conjunction with traditional cutting fluids in the form of mist or droplets to enhance their lubrication capability. Cooling action in gas-cooled machining is mainly through convection. The heat transfer by the gas jet can be controlled by controlling the jet velocity. Gases also provide inert atmosphere and lubrication. Air-chilled/cooled systems are a special case of gas-cooled systems. Air is a natural resource and it is readily available everywhere. The only processes required in air- cooling system are to compress, dry, and discharge the air with a set pressure.

\begin{tabular}{|c|c|c|c|c|c|c|c|}
\hline \multirow{3}{*}{ Substance } & \multicolumn{2}{|c|}{$\begin{array}{l}\text { Boiling point } \\
@ 101.325 \mathrm{kpa}\end{array}$} & \multicolumn{3}{|c|}{$\begin{array}{l}\text { Gas Phase Properties } \\
\left(00^{\circ} \mathrm{C} \& 101.325 \mathrm{kpa}\right.\end{array}$} & \multicolumn{2}{|c|}{$\begin{array}{l}\text { Liquid Phase Properties } \\
@ \text { @B.p.7@101.325 kpa }\end{array}$} \\
\hline & Temp. & $\begin{array}{c}\text { Latent Heat } \\
\text { of } \\
\text { Vaporization }\end{array}$ & $\begin{array}{l}\text { Specific } \\
\text { Gravity }\end{array}$ & $\begin{array}{c}\text { Specific } \\
\text { Heat } \\
\text { Cp }\end{array}$ & Density & $\begin{array}{l}\text { Specific } \\
\text { Gravity }\end{array}$ & $\begin{array}{c}\text { Specific } \\
\text { Heat } \\
\text { Cp }\end{array}$ \\
\hline & ${ }^{\circ} \mathrm{C}$ & $\mathrm{KJ} / \mathrm{Kg}$ & Ail $=1$ & $\mathrm{Kj} / \mathrm{kg}{ }^{\circ} \mathrm{C}$ & $\mathrm{KJ} / \mathrm{m} 3$ & Water $=1$ & $\mathrm{Kj} / \mathrm{kg}{ }^{\circ} \mathrm{C}$ \\
\hline Air & -194.3 & 205.0 & 1 & 1.01 & 1.2929 & 0.873 & 1.865 \\
\hline $\begin{array}{c}\text { Oxygen } \\
\mathrm{O}_{2}\end{array}$ & -182.96 & 213.0 & 1.113 & 0.9191 & 1.429 & 1.14 & 1.669 \\
\hline $\begin{array}{c}\text { Nitrogen } \\
\mathrm{N}_{2}\end{array}$ & -195.8 & 199.1 & 0.9737 & 1.04 & 1.2506 & 0.808 & 2.042 \\
\hline $\begin{array}{c}\text { Argon } \\
\text { Ar }\end{array}$ & -185.9 & 162.3 & 1.39 & 0.523 & 1.7837 & 1.40 & 1.078 \\
\hline $\begin{array}{c}\text { Carbon } \\
\text { dioxide } \\
\mathrm{CO}_{2}\end{array}$ & -78.5 & 571.3 & 1.539 & 0.85 & 1.9769 & 1.18 & -- \\
\hline
\end{tabular}

Cooling media of this technique is air, it could be defined as the cleanest and most environmentally friendly method of cooling in cutting operations [19]. There have been very few publications examining the effect of gas application in machining operations $[6,20]$. There are many approaches to cool air or gases such as: Liquid nitrogen evaporation refrigeration, vapor-compression refrigeration, adiabatic expansion refrigeration and vortex tube refrigeration [21]. In approach which used chilled /cooled and compressed air for cooling in machining operations have been attempted some researchers [21-28]. Y. Su et al [21, 25] developed new cooling gas equipment, Fig.1 shows the schematic diagram, which consisting of vapor-compression refrigeration system and semiconductor refrigeration system. A main function of vapor-compression refrigeration system in this system to reduce the temperature of water in order to enhance the efficiency of semiconductor refrigeration, the system works as: 1)When a thermopile is supplied with direct current; its heat energy is transferred from one side to another side due to Peltier effect of semiconductor materials. 2) Cold water that flows through the upper and lower heat absorbers carries away the heat at the hot side of the thermopile. Thus, the wall of the cooler may remain at extreme low temperature by close contact with the cold side of the thermopile. 3- After the compressed gas passes through the heat exchanger, it enters the cooler and is cooled by heat exchange with the wall of the cooler. 4-Cooled compressed gas will be jetted to the cutting zone at a certain pressure.

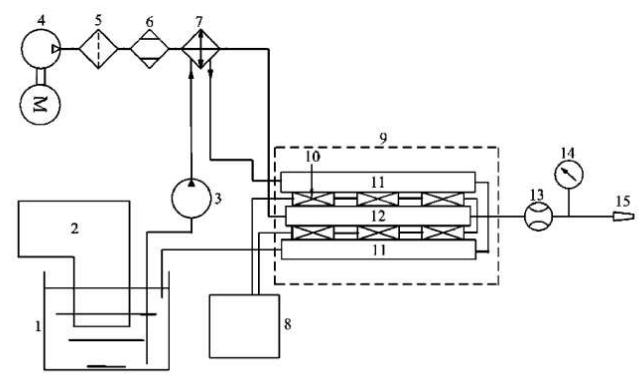

Where: 1) water container, (2) vapor compression refrigeration system, (3) water pump, (4)compressor, (5) filter, (6) drier, (7) heat exchanger, (8) control box, (9) semiconductor refrigeration system, (10) thermopile,(11) heat absorber,(12) cooler, (13) flow meter, (14) pressure gauge, (15) nozzle.

Fig-1: Schematic diagram of the new cooling gas equipment $[21,25]$ 
Y. Su et al [21] investigated with this approach on tool wear, surface finish and chip shape in finish turning of Inconel 718 nickel-base super alloy and high-speed milling, under different cooling/lubrication conditions, i.e. dry cutting, minimal quantity lubrication (MQL), cooling air and cooling air + minimal quantity lubrication (CAMQL). They concluded at cutting speed of $76 \mathrm{~m} / \mathrm{min}$ that applied of cooling air and CAMQL in finish turning of Inconel 718 was improved tool life $78 \%$ and $124 \%$ over dry cutting respectively. Chilled air as coolant in machining resulted in longer tool life. The effect of chilled air on the surface finish is highly dependent on the machining parameters. In general it could be claimed that air cooling produces lower surface roughness than dry cutting [21, 22]. Another approach for produced cooled air is by vortex tube [19, 29]. Fig.2. shows schematic of vortex tube. This tube consists of one inlet hole and two outlet holes, compressed air enters tangentially to a cylindrical chamber from inlet hole, the valve which is on the hot stream end adjusts cool air temperature, hot air temperature vortex tube exit temperatures and mass flow rates can be adjust for cooling capacity requirements.

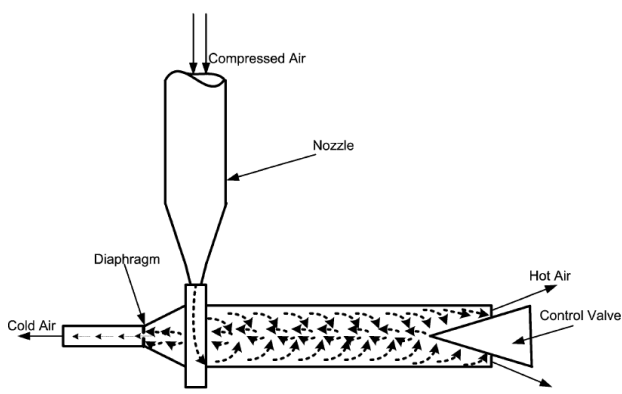

Fig-2: Schematic of vortex tube [19, 32]

One end of the cylinder is closed by a diaphragm which permits the escape of air only from the central region. The other end allows the flow of axial portion of the air. The air entering through the central diaphragm shows a reduced temperature, while the air escaping through the other end shows a temperature increase. The application of gases as cutting fluids goes back to 1930s [19], such us Nitrogen, Oxygen, Argon and carbon dioxide, these gases have been used in machining, instead of cutting fluids to prevent oxidation of the workpiece and the chips, There have been very few publications examining the effect of gas application in machining operations. Oxygen plays a very important role in creating oxides on the tool surface and freshly cut work material surfaces. These oxides "in the right places on the rake face" reduce friction and tool wear. Also it is able to penetrate for only a short distance e.g., $0.25 \mathrm{~mm}$ from the outer edge of the chip at $49 \mathrm{~m} / \mathrm{min}$ in cutting steel $[19,20]$. Nitrogen is lighter than air and can be dispersed into the atmosphere. Nitrogen in air plays an important role in reducing oxidation of the tool when cutting steel and other metals at high speeds [20]. Nitrogen and the inert characteristics of argon prevent the formation of surface films, allowing the chip to slide smoothly along the rake surface of the cutting tool [30]. Carbon dioxide can be particularly effective in reducing crater wear on carbide tools when machining titanium alloys, Inconels and other difficult to machine materials [31]. $\mathrm{CO}_{2}$ at high pressure is supplied through a hole in the tool and allowed to emerge from small channels under the tool tip as close as possible to the cutting edge. The expansion of the $\mathrm{CO}_{2}$ lowers the temperature, and the tool close to the jet is kept below $0{ }^{\circ} \mathrm{C}$ [20].

\subsection{Advantages of chilled air and gases}

1- Gaseous coolants are also beneficial when liquid coolants cannot be applied, such as heavy duty cutting conditions, because conventional cooling techniques fail to penetrate the chip-tool interface. 2- Nitrogen and Argon provide an inert environment which hcould prevent the cutting tool and machined surface from oxidation at high cutting temperatures, 3- Thermal energy transferred to the workpiece reduced by using compressed air and chilled air as compared to dry cutting, 4- Gaseous are relatively cleaner and more environmentally friendly. 5- Cold air is a kind of pressuring fluid; its flow should affect the broken manner of cutting chip. This is very important to finishing machining process, 6- Chilled air cooling in machining would improve machinability of hard-to-cut materials, and does provide safe-to-use coolant [19, 20, 32, 33].

\subsection{Disadvantages of chilled air and gases}

1) Chilled air and gases More expensive alternatives than cutting fluids which require additional equipment which normally are not provided with machine too; 2) Gases or chilled air cannot circulate in the machine tool and thus they are not reusable in the system as they vaporize after application; 3) $\mathrm{CO}_{2}$ as coolant there is a requirement for ventilation over the machining zone. This is due to the fact that $\mathrm{CO}_{2}$ is heavier than air and accumulates at the shop floor increasing the risk of oxygen depletion $[19,20]$.

\section{CRYOGENIC COOLING}

Cryogenic term studies and use materials at very low temperatures, below $-150{ }^{\circ} \mathrm{C}$. However, normal boiling points of permanent gases such as shown in table 2. Some applications of cryogenics in industry such as health, frozen food, electronics, manufacturing, automotive and aerospace particularly for cooling purposes [34]. In cryogenic machining a super cold medium, usually liquefied gases, is directed into the cutting zone in order to reduce the cutting zone temperature and cool down the tool and/or workpiece $[26,29]$. Common cryogenic coolants used in machining operations are liquid nitrogen $\left(\mathrm{LN}_{2}\right)$, liquid carbon dioxide $\left(\mathrm{LCO}_{2}\right)$, solid carbon dioxide (dry ice), liquid helium and air (usually temperatures above $-50^{\circ} \mathrm{C}$ ). Liquid nitrogen is the most commonly used element in cryogenics. It is produced industrially by fractional distillation of liquid air and is often referred to by the abbreviation, $\mathrm{LN}_{2}$. Nitrogen melts at $210.01{ }^{\circ} \mathrm{C}$ and boils at $-198.79{ }^{\circ} \mathrm{C}$, it is the most abundant gas, in fact, $78 \%$ of the air we breathe is nitrogen. It is a colorless, odorless, tasteless, safe, non-combustible, and noncorrosive [34]. These characteristics of liquid nitrogen have made it as a preferred coolant [11]. The liquid nitrogen in a cryogenic machining system quickly evaporates and 
returns to the atmosphere, leaving no residue to contaminate the workpiece, chips, machine tool, or operator, thus eliminating disposal costs [35]. Cryogenic machining has been explored since the 1950's. It is usually accompanied with changes in the properties of the workpiece and/or cutting tool materials, as a result of lowering the temperature, it could increase the strength and hardness, and lower the elongation percentage and fracture toughness of materials. In machining difficult-to-machine material such as titanium and nickel based alloys by used cryogenic cooling will decrease tool wear due to very low temperature at workepice/cutting tool interface [36]. Cryogenic machining may classify into four approaches as follows:

\subsection{Cryogenic pre-cooling the workpiece}

Also known as cryogenic cooling of work-piece and chip. The main objective of this approach is to change the material properties of the workpiece in order to enhance machinability [8, 37]. This approach may classify into methods, one cryogenic path which workpiece is usually submerged in a cryogen and other cryogenic spray. The cryogenic is sprayed onto the workpiece by using nozzle over the cutting point just before the tool contacts with the cutting point [38-40]. Pre-cooling the workpiece and enclosing the workpiece in a cryogenic bath are not practical in the production line and negatively increase the cutting force and the abrasion to the tool [41]. Truesdale and Shin [42], used insulated $4.7 \mathrm{~mm}$ diameter copper pipe with nozzle to spray $\mathrm{LN}_{2}$ on Udimet 720 nickel-based alloy just before the milling tool such that the area to be cut without effecting the coated carbide tool. The insulation was used to ensure the $\mathrm{LN}_{2}$ temperature retained until it delivered to cutting place. Ding and Hong [43] developed cryogenic delivered system as shown in Fig. 3. $\mathrm{LN}_{2}$ was applied to external workpiece surface before cutting process started. The nozzle in that system moving lift and right uniformly while the workpiece rotated. The thermocouple was used to senses temperatures on the external and internal surface to give cutting process start when temperatures of theses surface same with $\mathrm{LN}_{2}$ temperature. $\mathrm{LN}_{2}$ flow rate was set more than 0.32 gallon/minute to maintained workpiece temperature at $-196{ }^{\circ} \mathrm{C}$ throughout the cutting process. Another cooling system was developed by Hong et al.[44] $\mathrm{LN}_{2}$ was sprayed to cutting edge by nozzle which it shapes; size and position were selected so that the $\mathrm{LN}_{2}$ jet covers the chip arc. The flow of that $\mathrm{LN}_{2}$ was oriented parallel to the axial line of the curved chip faces as shown in Fig. 4. In this system $\mathrm{LN}_{2}$ was sprayed to chip faces to improve the chip breakability. Ahmed et al. [40] modified standard tool holder by two design. In first design the gas is directed towards the tool cutting edge, to cool the newly generated chips, whereas design two the discharging gas is directed away from the work piece, the evaporated gas was sprayed onto the chips to increase the chips embrittlement. Also keeping the cutting tool inserts at very low temperature and improves wear resistance.

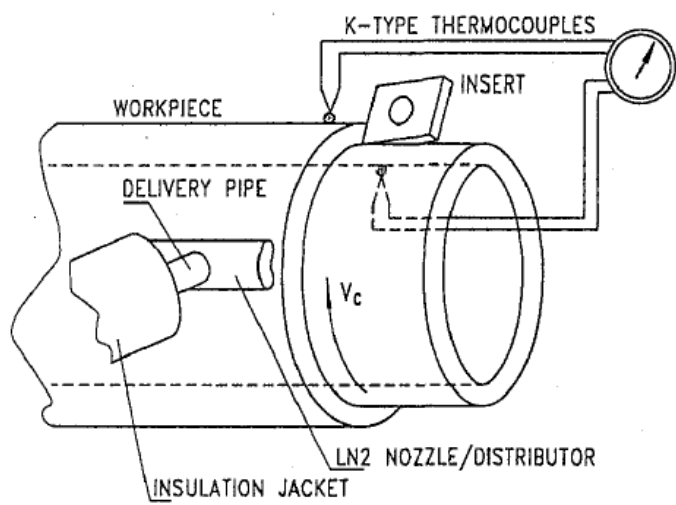

Fig-3: Cryogenic workepice pre-cooling [43]

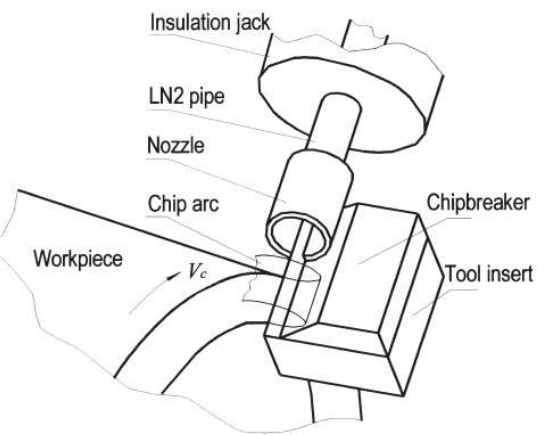

Fig-4: $\mathrm{LN}_{2}$ sprayed to chip face [44]

\subsection{Indirect cooling}

In this approach cutting tool was cooled thought heat conduction from a $\mathrm{LN}_{2}$ chamber which located under cutting tool insert. The cryogenic coolant is delivered to a chamber designed under or beneath cutting insert, therefore the cryogenic will absorbed the generated at cutting zone through conduction and evaporation, after that the evaporated cryogenic is then released to atmosphere from another hole which instilled in tool holder. By apply this approach in machining the performance will improved because the $\mathrm{LN}_{2}$ freeze the cutting tool without direct contact between the $\mathrm{LN}_{2}$ and the workpiece and cutting tool, also negative effect of cooling the workpiece such as material strength and hardness will be eliminated. however, the effect of this approach depend on thermal conductivity cutting tool material and insert thickness $[8,36]$. Wand and Rajurkar [37] designed a liquid nitrogen circulation system to keep the tool temperatures at a lower range. Sanchez et al. [45] developed a system based on a toolholder for turning processes with internal cooling using a coolant fluid (R-123) with liquid-gas phase change, flowing in a loop circuit. Fig.5. Illustrate the schematic of the tool holder. When coolant was evaporation allows an efficient heat exchange, thus an improvement in the removal heat at cutting zone. This refrigeration system is easy to fabricate, cheap and safe to environment, also it is closed system that does not consume coolant fluid. 


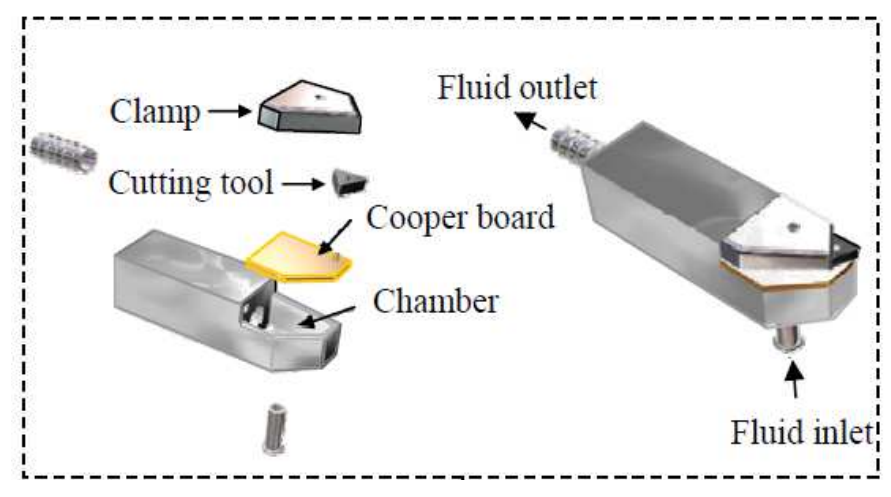

Fig-5: Illustrate the schematic of the tool holder [45]

\subsection{Spraying and jet cooling}

This approach widely used by many researchers. The objective in this approach of cryogenic coolants to cool cutting zone or the too/chip area, thus heat generated during cutting process will dissipated, therefore enhance the cutting tool properties. There are two methods to spry the cryogenic in to cutting zone using an external nozzle and modifying tool holder or cutting insert. consumption of $\mathrm{LN}_{2}$ is high in this approach and thus production cost could be high by spraying this coolant to cutting zone in machining operation [8, 37]. Fig. 6 . Illustrates the $\mathrm{LN}_{2}$ delivery nozzle assembly for turning operations was developed by Hong el al. [46]. The nozzle allow the cryogenic coolant jet to the tool rake face or to the flank face, or simultaneously to both. The chipbreaker helps to lift the formed chip from the tool rake face so that the $\mathrm{LN}_{2}$ jet can reach the tool-chip interface. The volumetric $\mathrm{LN}_{2}$ flow rate was $0.625 \mathrm{l} / \mathrm{min}$ for rake cooling $0.53 \mathrm{l} / \mathrm{min}$ for flank cooling and $0.814 \mathrm{l} / \mathrm{min}$ for both rake and flank cooling. They found The most effective cooling deliver the liquid to the rake face than the flank face. Matteo et al. [47] used Commercial tool holder, designed for internal lubrication (MIRCONA PCLNL 2525 EB) The tool holder has two injection nozzles for both rake and flank cooling.

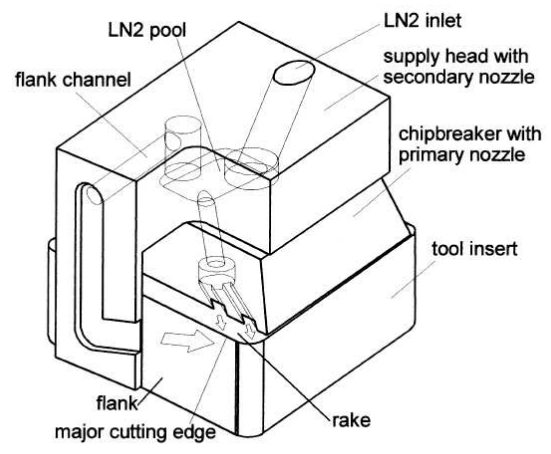

Fig-6: Illustrates the $\mathrm{LN}_{2}$ delivery nozzle assembly [47].

Dhananchezian et al. [48], was modified cutting tool insert (ISO K10 CNMG 120408 MP1- KC5010) for cryogenic cooling. A hole of diameter $2 \mathrm{~mm}$ at the rake face, it connected with main and auxiliary flank surface holes diameter $1 \mathrm{~mm}$ as shown in Fig.7. All these holes were made by EDM, main and auxiliary allowed a small amount of $\mathrm{LN}_{2}$ will reach major and cutting edges of the cutting tool insert. The evaporated gas from main flank surface hole will prevent excessive cooling of workpeice. Dhar et al. [49] and a Venugopal et al. [50] used external nozzles to jet $\mathrm{LN}_{2}$ along the main and auxiliary cutting edge. $\mathrm{LN}_{2}$ jet nozzles are along main cutting edge to protect the rake surface and principle flank and the other along the auxiliary cutting edge used to protect tool nose auxiliary flank to enable better surface finish and dimension accuracy. In milling operation, Dhokia et al. [51], designed an external jet system into cutting zone during end milling operations by considering the relative movement of the cutting tool with respect to the workepice. The aim of this jet cooling is to reduce the temperature at the cutting and alter the friction material hardness as a result of ultra-low temperature.

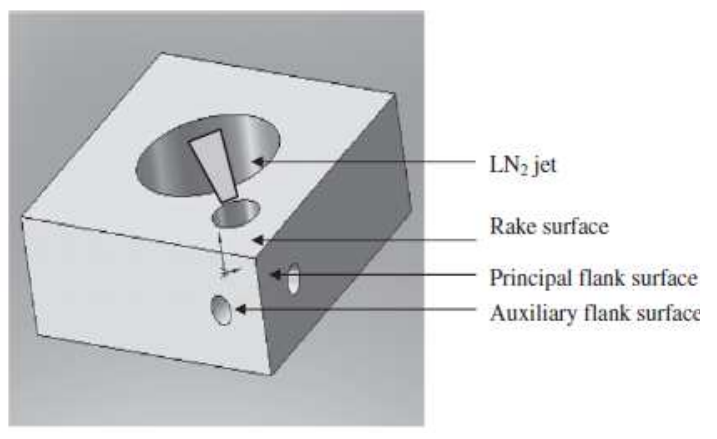

Fig-7: Schematic modified cutting insert with three holes[48]

For cryogenic cooling of the grinding zone, Li et al. [52] , designed a jet of liquid nitrogen system to delivery grinding medium from a suitable distance of $50 \mathrm{~mm}$ and angle of $15^{\circ}$. This cooling approach remove the BUE problem on the tools because the chips welding to the tool reduced by cold temperature. Also $\mathrm{LN}_{2}$ cannot be circulated inside the machine like conventional cooling fluids, because $\mathrm{LN}_{2}$ evaporated to atmosphere. This approach, optimization of the flow rate and application pressure of liquid nitrogen is important in order to get continuous flow of liquid nitrogen without over-cooling of the workpiece [35].

\subsection{Cryogenic treatment}

This approach similar to heat treatment is the process of deep-freezing materials at cryogenic temperature to improve the mechanical and physical properties of that treated materials. Whereas, cryogenic treatment of cutting tools to increase wear resistance and hardness therefore, reduces tool consumption and down time for machine tool setup. The whole process takes between 36 to 74 hours depending upon the type and weight of material under treatment. Generally Cryogenic treatment is classified in to type: Shallow cryogenic treatment, which material is subjected at $-110{ }^{\circ} \mathrm{C}$ stayed at this temperature for 18-25 hours and gradually brought back to the room temperature. Another type, deep cryogenic treatment, which material is subjected at $-196{ }^{\circ} \mathrm{C}$ and stayed at this temperature for 24-72 hours and 
gradually brought back to the room temperature [53] as shown in Fig. 8 .

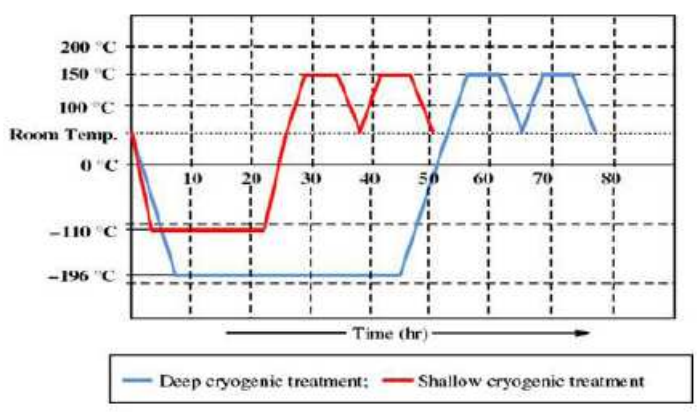

Fig- 8: cryogenic treatment cycle[53]

Thamizhmanii et al. [54] performed a deep cryogenic treatment of PVD inserts for milling process as follows: inserts is slowly cooled to $-196^{\circ} \mathrm{C}$ and soaked at deep cryogenic temperature for 20 hours. The inserts is then allowed to return slowly to the ambient temperature. The complete cryogenic cycle would take up to 25-30 hours. Gill et al. [55] studied cryogenic treatment of tungsten carbide under dry condition, which insert being treated were not exposed to the $\mathrm{LN}_{2}$ to eliminate the risk and damage of thermal shock. The steps of process as follows: inserts paled in a container and the temperature was brought $-196^{\circ} \mathrm{C}$. At each interval, the insets were allowed to stabilize in 2-h increments. The temperature was held constant for 24 hours before the process was reversed. The insert were slowly brought to room temperature allowing the material insert stabilize. Then the inserts were subject to two tempering cycle to relive the stress induced by cryogenic treatment. This was accomplished by increasing the temperature until $+150{ }^{\circ} \mathrm{C}$ and then slowly reducing the temperature back to room temperature at the rate of $0.5{ }^{\circ} \mathrm{C} / \mathrm{min}$. In this approach, many researches were investigated cutting tools, steel and polymer materials.

\subsection{Advantages of cryogenic cooling}

1) $\mathrm{LN}_{2}$ Cleaner and safer, environmentally- friendly liquid gases, thus no adverse health effects for personnel on the shop floor; 2) More effective at higher feed rate, because at higher feed rate chip thickness is higher, plastic deformation at the shear zone takes place at a faster rate, therefore generated more heat; 3) Cryogenic cooling of carbide tools turning machining, notching, abrasion, adhesion, and diffusion-type wear cab be retarded effectively, leading to remarkable improvement in tool wear; 4) Cryogenic coolants reduce the coefficient of friction at the interface tool-chip over the rake face. Thus, the cutting forces required in cryogenic cooling less than that required for dry cutting; 5) Improved product quality in machined parts through the elimination of mechanical and chemical degradation of machined surface; 6) Enhanced surface integrity through controllable microstructural and phase changes with more favorable dynamic recrystallization and corrosion and wear resistance; 7) By controlling jet $\mathrm{LN}_{2}$, which applied to the chip and tool rake face, tool life can be enhanced; 8) Micro-temperature manipulation with cryogenic cooling is the best means of chip control in the machining of difficult-to-cut materials such as titanium and nickel alloys [56-58].

\subsection{Disadvantages of cryogenic cooling}

1) The cost set-up is high; 2) Frozen action at the nozzle obstructs the flow of cryogenic coolants; 3) Overcooling the workepiece, if did not optimized of the flow rate and pressure $\mathrm{LN}_{2}$. Furthermore, this may lead to embrittlement of the workpiece material $[56,57]$.

\section{EFFECTS OF THE GAS-BASED COOLANT-}

\section{LUBRICANTS IN MACHINING PROCESSES}

Gas-based coolant-lubricants are used for effective and fast removal of heat generated during cutting operations and is used for almost all types of materials with properties ranging from ductile to brittle, and metallic to organic etc. It has been shown that Gas-based coolant-lubricants methods do provide better surface properties on the work-piece, extends tool life, reduces heat effects on work-piece, reduces dimensional deviations on work-piece, etc. Further it has been shown that Gas-based coolant-lubricants would increase machinability of hard-to-cut material. Health, safety and environmental friendliness of using cryogenics have made it attractive for the machining industry. Unlike conventional emulsion cutting fluids which are widely used, cryogenics such as liquid-nitrogen, dry ice, etc. do not create health or environmental hazards. Unlike the conventional cutting fluids, liquid nitrogen is not re-circulated in the machine tool system. Liquid nitrogen absorbs heat generated during cutting operation and evaporates as a gas and is released to the atmosphere, as it does not pollute the environment, or be harmful to people around [38, 46, 59].

\subsection{The effect of Gas-based coolant-lubricants on}

\section{cutting temperatures}

In the metal cutting process, the tool performs the cutting action by overcoming the shear strength of the workpiece material. Temperature at the tool-chip interface affects the contact phenomena by changing the friction conditions, which in turn affects the shape and location of both of the primary and secondary deformation zones. High cutting temperatures strongly influence tool wear, tool life, workpiece surface integrity, chip formation mechanism and contribute to the thermal deformation of the cutting tool, which is considered, amongst others, as the largest source of error in the machining process. Therefore, by using coolants is to reduce the cutting temperature through conduction. But at very high cutting temperatures the conventional cutting fluids evaporate before reaching the cutting zone and fail to penetrate into the tool/chip interface. Evaporation of the cutting fluids in contact with hot surfaces results in the formation of a hot vapour cushion at the cutting zone and over the hot surfaces which exacerbates the conduction and further increases the cutting zone temperature. Therefore 
Gas-based coolant-lubricants (chilled air/gases and cryogenic cooling) is an efficient way of maintaining the temperature at the cutting interface well below the softening temperature of the cutting tool material [60-63]. High cutting temperature is generated at the interface when high speed machining Inconel 718, which lowers the strength and hardness of the tool material and facilitates the thermally related wears such as adhesion and diffusion [21]. The low thermal conductivity of titanium-based alloys causes heat transfer to the tool that leads to rapid tool deterioration[16]. In the cooling air cutting of difficult-to-cut materials, cooling air was jetted to the cutting zone at a high pressure and dissipated the heat produced by the cutting process by means of convection [21]. In machining titanium and nickel alloys, the generation and the consequent increase in temperature in the cutting process play crucial roles in tool life and machine quality. With $\mathrm{LN}_{2}$ coolants circulating through a sealed cap which isolated on the top of the cutting insert to reduce cutting temperature. This technique has no negative effect on the workpiece and the temperatures in the tool life and workpiece can be largely decreased, because changing the convection condition surrounding the tool. Thus increases the useful life of the tool [37]. Su et al.[21] investigated the effect different cooling/lubrication conditions, i.e. dry cutting, minimal quantity lubrication (MQL), cooling air, and cooling air and minimal quantity lubrication (CAMQL) finish turning of Inconel 718 nickelbase super alloy, they obtained with CAMQL best tool life ,because an addition of a very small amount of cutting oil in chilled air stream further reduce cutting temperature by reducing the friction at the cutting interface. Also, evaporation of coolant oil will decreased the cutting temperature. Hong and Ding has studied the effect of different approaches: (i) dry cutting; (ii) indirect cryogenic cooling; (iii) emulsion coolant; (iv) cryogenic cooling of flank face; (v) cryogenic cooling of rake face and (vi) simultaneous cryogenic cooling of flank and rake faces.

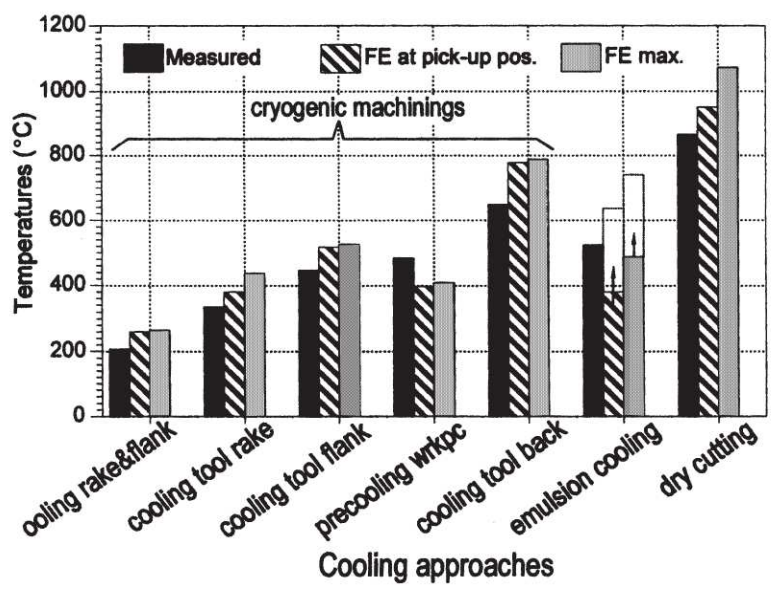

Fig-9: Measured and predicted tool temperature for different cooling approaches [21].

During turning of Ti-6Al-4V by cryogenic cooling, they found that simultaneously applying $\mathrm{LN}_{2}$ to the tool rake and flank can reduce tool temperatures to below $500{ }^{\circ} \mathrm{C}$. Fig.9.
Shows different cooling approaches lead to different cutting tool temperatures (measured and predicted). In cryogenic jet cooling with modified cutting tool insert in turning of a $\mathrm{Ti}-$ $6 \mathrm{Al}-4 \mathrm{~V}$ alloy, the cutting temperature at a cutting velocity of $97 \mathrm{~m} / \mathrm{min}$ and feed rate of $0.159 \mathrm{~mm} / \mathrm{rev}$ was $504{ }^{\circ} \mathrm{C}$ and $192^{\circ} \mathrm{C}$ for wet machining and cryogenic cooling respectively. It was observed that in this cooling approach, the cutting temperature was reduced by $62 \%$ over wet machining. This is because liquid nitrogen was directly applied to the heat generation zones through holes made in the cutting tool insert. The liquid nitrogen in the present method of application enabled the reduction in the cutting temperature by $61-66 \%$ over wet machining [48]. Therefore, by using cryogenic medium particularly $\mathrm{LN}_{2}$ as a coolant in different machining operations has been effective method to reduce cutting temperatures.

\subsection{The effect of Gas-based coolant-lubricants on}

\section{tool wear and tool life}

Tool wear is generally considered to be a result of mechanical (thermodynamic wear, mostly abrasion) and chemical (thermo-chemical wear, diffusion) interactions between the tool and workpiece. Adhesion means the recombination generated when the tool and the workpiece material come into contact with distance of atoms. Abrasive wear is the damage on a surface, which appears due to the motion relative to the surface of either harder asperities or perhaps hard inclusions trapped at the interface. The diffusion process involves the heat. In cutting process of Inconel 718 , the cutting temperature is very high; the close contact between the tool-chip and tool-workpiece provides an ideal environment for the atoms in the tool material with the external diffusion through the tool-chip interface. For the carbide tools, Co element is the easiest to diffusion loss, thus the Co content of carbide tools can determine the occurrence of diffusion wear [64]. Many researches were studied tool mechanisms in machining Inconel 718 alloys with different cutting tools, the main results as: With uncoated carbide tool K20, within the cutting speed range of $45-55 \mathrm{~m} / \mathrm{min}$, the dominant wear mechanisms are abrasive wear, chipping and plastic deformation [65]. With uncoated tungsten carbide (WC) and coated tools (single-layer (TiAlN) PVD, and triple-layer (TiCN/A $\left.1_{2} \mathrm{O}_{3} / \mathrm{TiN}\right) \mathrm{CVD}$ ) within the speed range of $50-100 \mathrm{~m} / \mathrm{min}$, federate range of $0.075-0.125 \mathrm{~mm} / \mathrm{rev}$ with a constant depth of cut of $0.25 \mathrm{~mm}$, adhesive wear and abrasive wear are the dominant wear mechanisms [66]. With the CBN tools, the dominant tool wear mechanisms are adhesive wear and diffusion wear due to the chemical affinity between the tool material and workpiece materials [67]. With the CC670 and CC680 ceramic tools, the dominant wear mechanism leading to the flank wear is chemical wear, the depth-of-cut (DOC) notch wear results in the micro-collapse and abrasive wear [68]. In machining titanium alloys, there were some specific studies on tool failure modes and wear mechanisms. Notching, flank wear, crater wear, chipping and catastrophic failure are the prominent failure modes when machining titanium 
alloys, these being caused by a combination of high temperature, high cutting stresses, the strong chemical reactivity of titanium, the formation process of catastrophic shear (lamellar) chips, etc. Plastic deformation can also be a major contributor to wear mechanisms of other tool materials when machining titanium alloys, especially in the case of high-speed machining, due to the presence of high compressive stresses and the development of high temperatures close to the cutting edge. The mechanism of attrition acts preferentially on the mixed carbide grains, and tools containing mixed carbides also wear by diffusion quicker than WC/Co tools because these mixed carbides dissolve preferentially in titanium. The rake and flank wear of the entire tool materials tested resulted from dissolutiondiffusion and attrition when turning titanium alloys. Dissolution-diffusion wear predominated on the 'rake face' of all the uncoated cemented carbides and ceramics, except for sialon, where attrition is the competitive wear mechanism [13]. Nose wear was the predominant tool failure mode observed when finish turning Inconel 718 with coated carbide inserts. dry cutting, minimal quantity lubrication (MQL), cooling air and cooling air with minimal quantity lubrication (CAMQL). When end of tool life was considered at $0.2 \mu \mathrm{m}$ nose wear, then cooling air and CAMQL, respectively, gave $79 \%$ and $124 \%$ improvement in tool life over dry cutting [21]. In contrast, cryogenic cooling significantly reduced the tool life of the coated solid carbide end mills due to the extent of chipping [51] .

Thamizhmanii at al. [54] were studied the tool performance (tool wear) between cryogenic treated and non-treated PVD inserts by milling process on Inconel 718 material. They found, cryogenic tool inserts formed low flank wear and the crater wear is also low at high cutting speed with high feed rate than non-treated inserts. Therefore increase tool life with cryogenic treated PVD inserts in machining Inconel 718. With nitrogen gas in high-speed milling of Ti-6Al-4V, the adhesion between chip and cutting edge was prevented, and the abrasion condition of tool was improved [69]. Tool wear rates when machining titanium alloy Ti-6Al-4V with cemented carbide using LN2 and under conventional cooling at cutting speed of $132 \mathrm{~m} / \mathrm{min}$, feed rate of 0.2 $\mathrm{mm} / \mathrm{rev}$ and a depth of cut of $1.0 \mathrm{~mm}$ showed a fivefold increase in flank wear for tools subjected to the conventional cooling [37]. Whereas, during the machining of Ti-6Al-4V alloy using uncoated microcrystalline K20 tungsten carbide inserts at $70 \mathrm{~m} / \mathrm{min}$ cutting speed, under Cryogenic cooling by LN2 decreased the growth of tool wear very effectively, therefore, enhancing the tool life to 24 min compared to 7 min under dry machining and 14 min under wet machining. Reason reduction in wear is seemingly because reductions of temperature-sensitive wear phenomena such as diffusion and adhesion, enabled by direct and indirect cooling with the liquid nitrogen jet. But under high velocities 100 and $117 \mathrm{~m} / \mathrm{min}$ such benefit will decreased due to improper penetration of liquid nitrogen in the chip- tool interface. Under cryogenic machining condition was observed flanking of the rake surface just at the end of the crater wear region was observed. This is attributed to higher thermal gradient at the end of the crater contact [70]. Flank wear was reduced by $27-39 \%$ in cryogenic jet cooling (with modified cutting tool inserts over that of wet machining for turning Ti-6Al-4V alloy. This is due to the control of the abrasion and attrition wear mechanisms through a reduction in the cutting zone temperature and less adhesion between the chip-tool and work-tool interactions by the application of liquid nitrogen at the cutting zones. Thus, Cryogenic cooling enabled a substantial reduction in the geometry of tool wear through the control of the tool wear mechanisms [48]. Strano et al. [47] demonstrated that cryogenic het cooling with two injection nozzles for both rake and flank is able to increase the tool life by about $40 \%$ with respect to wet cutting. Nath et al.[71] have been observed that the combination of lower pressure (150 psi) air-mixed $\mathrm{CO}_{2}$ with a higher flow rate $(20 \mathrm{ml} / \mathrm{min})$ and a larger spray distance $(35 \mathrm{~mm})$ in machining titanium alloys, produces a significantly longer tool life and broken chips. The results also reveal that the atomization-based cutting fluid ACF spray system can extend tool life up to $40-50 \%$ over flood cooling. Another study conducted by, Machai et al. [72], were compared various cooling techniques in machining of various tempers of $\beta$-titanium alloy, which consisted of following: conventional flood emulsion; impingement of jet of $\mathrm{CO}_{2}$-snow at the rake face, the flank face, the rake and flank faces together; and the combination of the $\mathrm{CO}_{2}$-jet and MQL. The main conclusion was: The adhesion wear is significantly dependent on the cutting speed, while the abrasion wear is mainly dependent on the hard phases present in the microstructure. Application $\mathrm{CO}_{2}$ snow cooling jet at the rake face, cases better suppression of tool wear as compared to the flood emulsion. Application of MQL at rake face in conjunction with that of $\mathrm{CO}_{2}$ snow at flank face is slightly better than application of $\mathrm{CO}_{2}$ snow at both faces, with regard to tool damage. In comparison with difference cooling methods for machining gamma titanium aluminides, the best out comes were obtained with cryogenic machining: liquid nitrogen cooling decreases VB max up to $61 \%$ in comparison with conventional lubrication. As shown in Fig.10. The improvement of effective cooling action due to the extremely lower temperature of the cooling medium increases the thermal gradient between cutting zone and tool, with a higher heat removal and a huge reduction of the thermal load of the cutting edge [73].

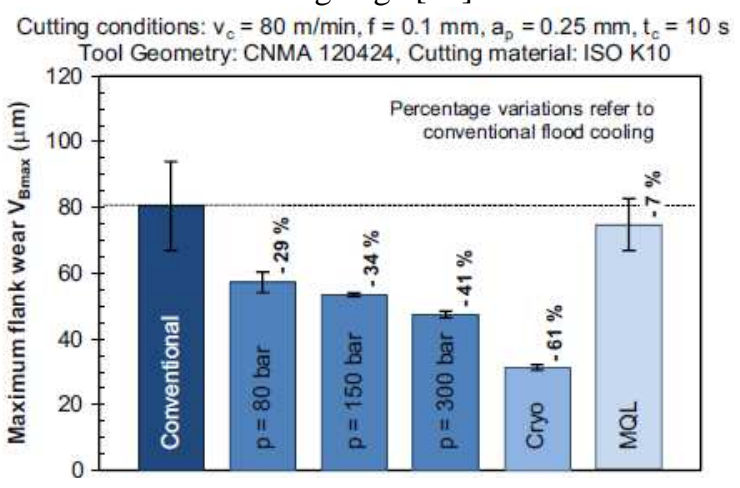

Fig-10: Tool wear results after a cutting time $t_{c}=10 \mathrm{~s}[73]$

In hybrid cryogenic machining method such as, ultrasonic vibration assisted machining (UVC), The tool flank wear was found to be about $9-14 \%$ of that in the conventional 
machining method. Therefore, the tool life with the UVC method is increased by at least 4-8 times over the conventional machining method [74].

\subsection{The effect of Gas-based coolant-lubricants on}

\section{surface integrity/surface roughness}

The characteristics which considered as surface integrity factors are ,surface roughness, microcracking, phase transformations, hardness variations, tears and laps related to built-up edge formation, residual stress distribution ,etc. When critical structural components in aerospace industry are machined with the objective to reach high reliability levels, surface integrity is one of the most relevant parameters used for evaluating the quality of machined surface. The residual stresses induced by machining of titanium alloys and nickel-based alloys are very critical due to safety and sustainability concerns. Surface roughness is generated from two components, the ideal or geometric finish and natural finish. While the ideal or geometric finish results from the geometry and kinematic motions of the tool, the natural finish can result from vibrations, tool wear or built-up edge formation, etc.[1, 36, 75, 76]. Main surface defects observed during machining titanium- and nickelbased alloys are surface drag, material pull-out/cracking, feed marks, adhered material particles, tearing surface, chip layer formation, debris of microchips, surface plucking, deformed grains, surface cavities, slip zones, laps (material folded onto the surface), and lay patterns. In determining the surface roughness, it was found that the high temperatures occurring during machining of titanium and nickel-based alloys is the main reason for high surface roughness values. Also, the built-up layer created at the cutting location might push the tool from its original route[1]. When machining Inconel 718 under the application of cooling air and CAMQL, the drastic reduction of surface roughness values was attributed to the reduction in tool nose wear under these two cooling/lubrication conditions [21]. Dhokia et al.[51] presented first studied on the cryogenic CNC milling of Inconel 718 nickel based alloy. With PVD TiAlN coated solid carbide end mills comparison with dry, cryogenic cooling has resulted in $33 \%$ and $40 \%$ reduction in $\mathrm{Ra}$ and ISO Rz surface roughness of the machined parts as compared to dry machining. Kenda et al. [77] and Pusavec et al .[75] were presented a new knowledge on surface integrity in terms or residual stresses, plastic work, and hardness in machining of Inconel 718 under cryogenic conditions and compares this with dry and MQL machining. Under cryogenic machining conditions (external jet nozzles), the stresses beneath the surface decreased up to $60 \%$. Cryogenic machining slightly influences the final product microstructure (smaller grain size), and induces less plastic deformation on the machined surface. Plastic deformations on the machined surface, in the direction of cutting speed, can be recognized just up to $1-2 \mu \mathrm{m}$ beneath the surface in cryogenic machining, while this plastic deformation zone is thicker and reaches up to $5-10 \mu \mathrm{m}$ in dry and MQL machining. The work hardened sub-surface layer was found to have a depth of about $40 \mu \mathrm{m}$, while a decreasing trend for this value is observed in the case of cryogenic machining. This means that in case of cryogenic machining a higher hardness on the surface is achieved, and this hardened layer is thinner than in dry or MQL machining. In cryogenic treated PVD inserts performed in maintaining low roughness, because cutting edge was not disturbed either by wear or by the heat at cutting zone. The surface roughness was low with cryogenic treated inserts in comparison with non-treated inserts for all cutting speeds [54]. In milling machining Udimet 720 (nickel-based alloys), the Cryogenic coolant yielded positive results by increasing the maximum cutting velocity from $10 \mathrm{~m} / \mathrm{min}$ to $120 \mathrm{~m} / \mathrm{min}$. Microstructural analysis confirmed that the smearing and plucking mechanisms are retarded by the slowing or elimination of the diffusion process [42]. In hybrid machining for machining Inconel 718, Feyzi at al.[74] were used cryogenic cooling (inderict cooling approach) with ultrasonic vibration assisted machining (UVC). They found minimum surface roughness $\mathrm{Ra}=0.2$ $\mu \mathrm{m}$ was achieved with the hybrid method, whereas $\mathrm{Ra}=2.5$ $\mu \mathrm{m}$ was achieved with the conventional machining method for the same cutting condition. Hence, the cutting quality with the hybrid method was improved by about 88-93\% over the conventional machining method. whereas, Wang et al. [78] were used cryogenic cooling [indirect cooling approach] with plasma heating. They found a $250 \%$ improvement in surface roughness compared with conventional machining titanium with compressed nitrogen gas, surface finish was found to be greatly improved with nitrogen gas as surface roughness of machine surface was $0.13 \mu \mathrm{m}$ in nitrogen gas machining while being $0.43 \mu \mathrm{m}$ in conventional machining. therefore cryogenic machining with high pressure nitrogen gas favors high speed machining [79]. For turning Ti-6Al-4V with cemented carbide insert, when $\mathrm{LN}_{2}$ cooling (indirect cryogenic cooling) was applied, the $R$ value of the alloy surface a after being machined for a length of $108 \mathrm{~mm}$ was $1.9 \mu \mathrm{m}$. When $\mathrm{LN}_{2}$ cooling was not applied, the $R$ value of the a workpiece surface after being machined for a length of $40 \mathrm{~mm}$ was $15 \mu \mathrm{m}$. Whereas, the surface roughness of Inconel 718 after being machined for $65 \mathrm{~mm}$ in length. With $\mathrm{LN}_{2}$ cooling, $R$ was $1.5 \mu \mathrm{m}$. When $\mathrm{LN}_{2}$ cooling was not applied, $R$ of the workpiece was 7.8 $\mu \mathrm{m}$ [37]. In jet Cryogenic machining reduced the surface roughness to a maximum of $39 \%$ over wet machining respectively in turning of the $\mathrm{Ti}-6 \mathrm{Al}-4 \mathrm{~V}$ alloy with modified cutting tool inserts [48]. In comparison between conventional flood cooling and high pressure lubricoolant supply (wet conditions), cryogenic cooling with liquid nitrogen, and minimum quantity lubrication (MQL), Klocke et al. [73], were investigated in longitudinal external turning operations. In terms of surface roughness the lowest indicates have been achieved with the liquid nitrogen as a comparison with other lubrication/cooling techniques. Fig.11. Shows a comparison between the arithmetic mean roughness $R_{a}$ and the maximum roughness profile height $R_{t}$, as a function of lubrication/cooling techniques. 


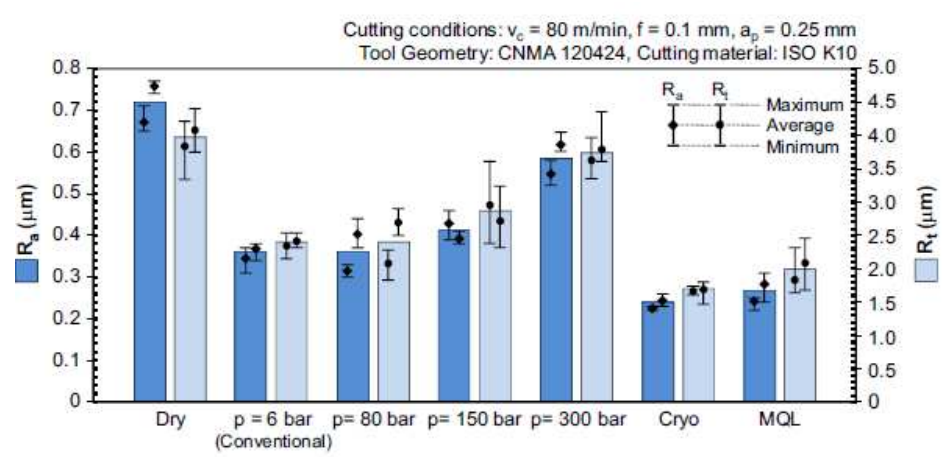

Fig-11: Surface roughness results as a function of lubrication/cooling techniques [73].

\section{CONCLUSION}

When compared with dry cutting and conventional cooling, for machining titanium and nickel alloys the most considerable characteristics of the Gas-based coolantlubricants application in machining operations could be determined as enabling substantial improvement:

1) Sustainable machining (cleaner, safer, and environmental-friendly method).

2) Productivity is also high, as cryogenic cooling shows better results at higher feed rates.

3) Increase in tool wear and with reduced cutting tool changeover costs, resulting in higher productivity.

4) Tool life improves dramatically owing to the fact that cryogen is able to penetrate the chip-tool interface.

5) Improved machined part surface quality/integrity with the absence of mechanical and chemical degradation of machined surface.

Further research in chilled air/gases cooling for nickel-based alloys, also cryogenic cooling machining using other machining operations such as milling and drilling with different tool-work piece materials is essential.

\section{ACKNOWLEDGEMENTS}

Special thanks to my main and core supervisors: Dr. Norizah, Prof .Dr. Noordin and staff of sultanah zanariah library, for their support and constructive and helpful comments of this paper

\section{REFERENCES}

[1] D. Ulutan and T. Ozel, Machining induced surface integrity in titanium and nickel alloys: a review, International Journal of Machine Tools and Manufacture, vol. 51, pp. 250-280, 2011.

[2] E. Ezugwu, High speed machining of aero-engine alloys, Journal of the Brazilian society of mechanical sciences and engineering, vol. 26, pp. 1-11, 2004.

[3] V. I. Babitsky, V. V. Silberschmidt, A. Roy, and A. Maurotto, Analysis of machinability of Ti-and Ni-based alloys, Solid State Phenomena, vol. 188, pp. 330-338, 2012.
[4] M. El Baradie, Cutting fluids: Part II. Recycling and clean machining, Journal of Materials Processing Technology, vol. 56, pp. 798-806, 1996.

[5] A. Shokrani, V. Dhokia, and S. T. Newman, Environmentally conscious machining of difficult-tomachine materials with regard to cutting fluids, International Journal of Machine Tools and Manufacture, vol. 57, pp. 83$101,2012$.

[6] M. El Baradie, Cutting fluids: Part I. characterisation, Journal of Materials Processing Technology, vol. 56, pp. 786-797, 1996.

[7] D. Lung, F. Klocke, and A. Krämer, High Performance Cutting of Aerospace Materials, Advanced Materials Research, vol. 498, pp. 127-132, 2012.

[8] Y. Yildiz and M. Nalbant, A review of cryogenic cooling in machining processes, International Journal of Machine Tools and Manufacture, vol. 48, pp. 947-964, 2008.

[9] M. J. Donachie, Superalloys: a technical guide: ASM international, 2002.

[10] J. K. Wessel, The handbook of advanced materials: enabling new designs: John Wiley \& Sons, 2004.

[11] "<a-09-02311-aerospace-catalog.pdf>."

[12] E. Ezugwu, J. Bonney, and Y. Yamane, An overview of the machinability of aeroengine alloys, Journal of Materials Processing Technology, vol. 134, pp. 233-253, 2003.

[13] E. Ezugwu and Z. Wang, Titanium alloys and their machinability - a review, Journal of Materials Processing Technology, vol. 68, pp. 262-274, 1997.

[14] R. Arunachalam, M. Mannan, and A. Spowage, Surface integrity when machining age hardened Inconel 718 with coated carbide cutting tools, International Journal of Machine Tools and Manufacture, vol. 44, pp. 1481-1491, 2004.

[15] I. Choudhury and M. El-Baradie, Machinability of nickel-base super alloys: a general review, Journal of Materials Processing Technology, vol. 77, pp. 278-284, 1998.

[16] S. H. I. Jaffery and P. T. Mativenga, Wear mechanisms analysis for turning Ti-6Al-4V—-towards the development of suitable tool coatings, The International Journal of Advanced Manufacturing Technology, vol. 58, pp. 479-493, 2012.

[17] X. Yang and C. Richard Liu, Machining titanium and its alloys, Machining Science and Technology, vol. 3, pp. 107-139, 1999.

[18] U. I. G. Inc, Gas properties, uses, applications, http://www.uigi.com, acess on 23 june 2013.

[19] U. S. Dixit, D. Sarma, and J. P. Davim, Environmentally friendly machining: Springer, 2012.

[20] M. C. Shaw, Metal cutting principles vol. 2: Oxford University Press New York, 2005.

[21] Y. Su, N. He, L. Li, A. Iqbal, M. Xiao, S. Xu, et al., Refrigerated cooling air cutting of difficult-to-cut materials, International Journal of Machine Tools and Manufacture, vol. 47, pp. 927-933, 2007.

[22] S. Sun, M. Brandt, and M. Dargusch, "Machining Ti-6Al-4V alloy with cryogenic compressed air cooling," 
International Journal of Machine Tools and Manufacture, vol. 50, pp. 933-942, 2010.

[23] S. Kim, D. Lee, M. Kang, and J. Kim, Evaluation of machinability by cutting environments in high-speed milling of difficult-to-cut materials, Journal of materials processing technology, vol. 111, pp. 256-260, 2001.

[24] Y. Su, N. He, L. Li, and X. Li, An experimental investigation of effects of cooling/lubrication conditions on tool wear in high-speed end milling of Ti-6Al-4V, Wear, vol. 261, pp. 760-766, 2006.

[25] L. Li, N. He, and Y. Su, Effect of Cryogenic Minimum Quantity Lubrication (CMQL) on Cutting Temperature and Tool Wear in High-Speed End Milling of Titanium Alloys, Applied Mechanics and Materials, vol. 34, pp. 1816-1821, 2010.

[26] S. Yuan, L. Yan, W. Liu, and Q. Liu, Effects of cooling air temperature on cryogenic machining of Ti-6Al4V alloy, Journal of Materials Processing Technology, vol. 211, pp. 356-362, 2011.

[27] J. Yao, Y. F. Liu, H. Zhang, H. H. Zhao, Y. L. Cai, and H. T. Huang, An Experimental Investigation of Cooling-Air Grinding Performance, Advanced Materials Research, vol. 97, pp. 1879-1882, 2010.

[28] S. Zhang, J. Li, and Y. Wang, Tool life and cutting forces in end milling Inconel 718 under dry and minimum quantity cooling lubrication cutting conditions, Journal of Cleaner Production, vol. 32, pp. 81-87, 2012.

[29] B. Yalçın, A. Özgür, and M. Koru, The effects of various cooling strategies on surface roughness and tool wear during soft materials milling, Materials \& Design, vol. 30, pp. 896-899, 2009.

[30] V. Cristino, P. Rosa, and P. Martins, Cutting under active and inert gas shields: A contribution to the mechanics of chip flow, International Journal of Machine Tools and Manufacture, vol. 50, pp. 892-900, 2010.

[31] L. Walter, Carbon Dioxide as Cutting Tool Coolant Repays Research with Imposing Savings, Canadian Machining and Metalworking, vol. 76, No. 8 Aug. 1965.

[32] Y. Ying, T. Mingwei, and W. Zhijuan, Effects of cryogenic cold air jet cutting on chip break in metal machining, 重庆大学学报 (英文版), vol. 3, 2004.

[33] S. Senevirathne and M. Fernando, Effect of Cryogenic Cooling on Machining Performance on Hard to Cut Metals-A Literature Review.

[34] http://en.wikipedia.org/wiki/Cryogenic, access on 28 june 2013.

[35] S. Y. Hong, Economical and ecological cryogenic machining, Journal of manufacturing science and engineering, vol. 123, pp. 331-338, 2001.

[36] A. Shokrani, V. Dhokia, P. Munoz-Escalona, and S. Newman, State-of-the-art cryogenic machining and processing, International Journal of Computer Integrated Manufacturing, pp. 1-33, 2013.

[37] Z. Wang and K. Rajurkar, Cryogenic machining of hard-to-cut materials, Wear, vol. 239, pp. 168-175, 2000.

[38] D. Bhattacharyya, M. Allen, and S. Mander, Cryogenic machining of Kevlar composites, MATERIAL AND MANUFACTURING PROCESS, vol. 8, pp. 631-651, 1993.
[39] S. Y. Hong and Y. Ding, Micro-temperature manipulation in cryogenic machining of low carbon steel, Journal of Materials Processing Technology, vol. 116, pp. 22-30, 2001.

[40] M. I. Ahmed, A. F. Ismail, Y. Abakr, and A. Amin, Effectiveness of cryogenic machining with modified tool holder, Journal of materials processing technology, vol. 185, pp. 91-96, 2007.

[41] S. Y. Hong, I. Markus, and W.-c. Jeong, New cooling approach and tool life improvement in cryogenic machining of titanium alloy Ti-6Al-4V, International Journal of Machine Tools and Manufacture, vol. 41, pp. 2245-2260, 2001.

[42] S. L. Truesdale and Y. C. Shin, Microstructural analysis and machinability improvement of Udimet 720 via cryogenic milling, Machining Science and Technology, vol. 13, pp. 1-19, 2009.

[43] Y. Ding and S. Hong, Improvement of chip breaking in machining low carbon steel by cryogenically precooling the workpiece, Journal of manufacturing science and engineering, vol. 120, pp. 76-83, 1998.

[44] S. Y. Hong, Y. Ding, and R. G. Ekkens, Improving low carbon steel chip breakability by cryogenic chip cooling, International Journal of Machine Tools and Manufacture, vol. 39, pp. 1065-1085, 1999.

[45] L. E. Sanchez, V. L. Scalon, and G. G. Abreu, Cleaner machining through a toolholder with internal cooling, in Proceedings of third international workshop on advances in cleaner production, São Paulo, Brazil, May, 2011, pp. 18-20.

[46] S. Y. Hong, Y. Ding, and W.-c. Jeong, Friction and cutting forces in cryogenic machining of Ti-6Al-4V, International Journal of Machine Tools and Manufacture, vol. 41, pp. 2271-2285, 2001.

[47] M. Strano, E. Chiappini, S. Tirelli, P. Albertelli, and M. Monno, Comparison of Ti6Al4V machining forces and tool life for cryogenic versus conventional cooling, Proceedings of the Institution of Mechanical Engineers, Part B: Journal of Engineering Manufacture, 2013.

[48] M. Dhananchezian and M. Pradeep Kumar, Cryogenic turning of the Ti-6Al-4V alloy with modified cutting tool inserts, Cryogenics, vol. 51, pp. 34-40, 2011.

[49] N. Dhar, S. Paul, and A. Chattopadhyay, The influence of cryogenic cooling on tool wear, dimensional accuracy and surface finish in turning AISI 1040 and E4340C steels, Wear, vol. 249, pp. 932-942, 2001.

[50] K. Venugopal, R. Tawade, P. Prashanth, S. Paul, and A. Chattopadhyay, Turning of titanium alloy with TiB2coated carbides under cryogenic cooling, Proceedings of the Institution of Mechanical Engineers, Part B: Journal of Engineering Manufacture, vol. 217, pp. 1697-1707, 2003.

[51] V. Dhokia, S. Newman, and R. Imani-Asrai, An initial study of the effect of using liquid nitrogen coolant on the surface roughness of Inconel 718 nickel-based alloy in CNC milling, Procedia CIRP, vol. 3, pp. 121-125, 2012.

[52] C. H. Li, Y. C. Ding, and Y. L. Hou, Investigation into the Grindability and Surface Integrity of the Nickel Base Superalloy Using Liquid Nitrogen Jet Grinding, Key Engineering Materials, vol. 426, pp. 49-54, 2010. 
[53] M. S. B. Chaudhari, S. P. Shekhawat, and M. A. S. Kushwaha, Advanced Technology of Cryoprocessing for the Enhancement of Tool Material Machining Characteristics: A Review.

[54] S. Thamizhmanii, M. Nagib, and H. Sulaiman, Performance of deep cryogenically treated and non-treated PVD inserts in milling, Journal of achievements in Materials \& Manufacturing Engineering, vol. 49, pp. 460-466, 2011.

[55] S. S. Gill, R. Singh, H. Singh, and J. Singh, Wear behaviour of cryogenically treated tungsten carbide inserts under dry and wet turning conditions, International Journal of Machine Tools and Manufacture, vol. 49, pp. 256-260, 2009.

[56] V. S. Sharma, M. Dogra, and N. Suri, Cooling techniques for improved productivity in turning, International Journal of Machine Tools and Manufacture, vol. 49, pp. 435-453, 2009.

[57] V. Sharma, M. Dogra, and N. Suri, Advances in the turning process for productivity improvement-a review, Proceedings of the Institution of Mechanical Engineers, Part B: Journal of Engineering Manufacture, vol. 222, pp. 14171442, 2008.

[58] D. Umbrello, Z. Pu, S. Caruso, J. Outeiro, A. Jayal, O. Dillon, et al., The effects of Cryogenic Cooling on Surface Integrity in Hard Machining, Procedia Engineering, vol. 19, pp. 371-376, 2011.

[59] M. Bermingham, S. Palanisamy, D. Kent, and M. Dargusch, A comparison of cryogenic and high pressure emulsion cooling technologies on tool life and chip morphology in Ti-6Al-4V cutting, Journal of Materials Processing Technology, vol. 212, pp. 752-765, 2012.

[60] Y. Takeuchi, M. Sakamoto, and T. Sata, Improvement in the working accuracy of an NC lathe by compensating for thermal expansion, Precision Engineering, vol. 4, pp. 19-24, 1982.

[61] G. Barrow, Review of experimental and theoretical techniques for assessing cutting temperatures, CIRP, 1973 , 22,(2), 203-2 11, 1974.

[62] E. Abele and B. Fröhlich, High speed milling of titanium alloys, Advances in Production Engineering \& Management, vol. 3, 2008.

[63] E. Ezugwu, Key improvements in the machining of difficult-to-cut aerospace superalloys," International Journal of Machine Tools and Manufacture, vol. 45, pp. 1353-1367, 2005.

[64] D. Zhu, X. Zhang, and H. Ding, Tool wear characteristics in machining of nickel-based superalloys, International Journal of Machine Tools and Manufacture, 2012.

[65] D. Thakur, B. Ramamoorthy, and L. Vijayaraghavan, Study on the machinability characteristics of superalloy Inconel 718 during high speed turning, Materials \& Design, vol. 30, pp. 1718-1725, 2009.

[66] A. Bhatt, H. Attia, R. Vargas, and V. Thomson, Wear mechanisms of WC coated and uncoated tools in finish turning of Inconel 718, Tribology International, vol. 43, pp. 1113-1121, 2010.

[67] J. Costes, Y. Guillet, G. Poulachon, and M. Dessoly, Tool-life and wear mechanisms of CBN tools in machining of Inconel 718, International Journal of Machine Tools and Manufacture, vol. 47, pp. 1081-1087, 2007.

[68] G. Brandt, A. Gerendas, and M. Mikus, Wear mechanisms of ceramic cutting tools when machining ferrous and non-ferrous alloys, Journal of the European Ceramic Society, vol. 6, pp. 273-290, 1990.

[69] Y.-1. KE, H.-y. DONG, G. LIU, and M. ZHANG, Use of nitrogen gas in high-speed milling of Ti-6Al-4V, Transactions of Nonferrous Metals Society of China, vol. 19, pp. 530-534, 2009.

[70] K. Venugopal, S. Paul, and A. Chattopadhyay, Growth of tool wear in turning of Ti-6Al-4V alloy under cryogenic cooling, Wear, vol. 262, pp. 1071-1078, 2007.

[71] C. Nath, S. G. Kapoor, R. E. DeVor, A. K. Srivastava, and J. Iverson, Design and evaluation of an atomization-based cutting fluid spray system in turning of titanium alloy, Journal of Manufacturing Processes, vol. 14, pp. 452-459, 2012.

[72] C. Machai, A. Iqbal, D. Biermann, T. Upmeier, and S. Schumann, On the Effects of Cutting Speed and Cooling Methodologies in Grooving Operation of Various Tempers of $\beta$-Titanium Alloy, Journal of Materials Processing Technology, 2013.

[73] F. Klocke, L. Settineri, D. Lung, P. Claudio Priarone, and M. Arft, High performance cutting of gamma titanium aluminides: Influence of lubricoolant strategy on tool wear and surface integrity, Wear, 2013.

[74] T. Feyzi and S. M. Safavi, Improving machinability of Inconel 718 with a new hybrid machining technique, The International Journal of Advanced Manufacturing Technology, pp. 1-6, 2013.

[75] F. Pusavec, H. Hamdi, J. Kopac, and I. Jawahir, Surface integrity in cryogenic machining of nickel based alloy-Inconel 718, Journal of Materials Processing Technology, vol. 211, pp. 773-783, 2011.

[76] I. Jawahir, E. Brinksmeier, R. M'Saoubi, D. Aspinwall, J. Outeiro, D. Meyer, et al., Surface integrity in material removal processes: Recent advances, CIRP AnnalsManufacturing Technology, vol. 60, pp. 603-626, 2011.

[77] J. Kenda, F. Pusavec, and J. Kopac, Analysis of residual stresses in sustainable cryogenic machining of nickel based alloy-Inconel 718, Journal of manufacturing science and engineering, vol. 133, 2011.

[78] Z. Wang, K. Rajurkar, J. Fan, S. Lei, Y. Shin, and G. Petrescu, Hybrid machining of Inconel 718, International Journal of Machine Tools and Manufacture, vol. 43, pp. 1391-1396, 2003.

[79] V. Venkatesh, T. T. Mon, J. Ramli, A. Jeefferie, and S. Sharif, Performance of cryogenic machining with nitrogen gas in machining of titanium, Applied Mechanics and Materials, vol. 52, pp. 2003-2008, 2011. 